\title{
Review
}

\section{Apoptosis: unmasking the executioner}

\author{
Mark R. Wilson \\ Department of Biological Sciences, University of Wollongong, Northfields \\ Avenue, Wollongong, NSW. 2522. Australia. tel: 61-42-214-534; \\ fax: 61-42-214-135; email: Mark_Wilson@uow.edu.au
}

Received 22.12.97; revised 20.2.98; accepted 20.3.98

Edited by D. Green

\begin{abstract}
The execution phase of apoptosis is comprised of those processes that commit cells to apoptotic death. Many independent studies have implicated mitochondria as playing a critical role in apoptotic execution. The activation of caspase- 3 and subsequent late stage degradative events are probably triggered by the release of proteins (such as cytochrome c) from the intermembrane space of mitochondria. The mechanisms responsible for this release are controversial but may include mitochondrial permeability transition and bcl-2-regulated swelling of the mitochondrial matrix. Two theoretical models of execution are discussed. It is important to note that some critical features of these models are largely based on data acquired from cell-free studies. Further studies with intact cells are urgently needed to test the physiological validity of these models.
\end{abstract}

Keywords: mitochondria; permeability transition; cytochrome c; caspases

\begin{abstract}
Abbreviations: AIF: apoptosis inducing factor; ANT: adenine nucleotide translocator; dATP: 3'-deoxyadenosine 5'-triphosphate; DFF: DNA fragmentation factor; FADD: Fas-associated death domain protein; FLICE: FADD-like ICE (caspase-8); hhCed-4: human homologue of Ced-4; ICE: interleukin- $1 \beta$-converting enzyme (caspase-1); $\psi$ mit: mitochondrial membrane potential; PT: mitochondrial permeability transition; ROS: reactive oxygen species
\end{abstract}

\section{Introduction}

Apoptosis is a genetically controlled active cell death process implicated as being a critical physiological mechanism involved in development and tissue homeostasis. The machinery of apoptotic cell death is highly conserved throughout evolution, with many similarities between phylogenetically divergent groups including invertebrates and humans. Apoptosis has been implicated in a variety of serious disease states, including acquired immunodeficiency syndrome (AIDS), cancers, Alzheimer's disease, stroke
(Whyte, 1996), and rheumatoid arthritis (Hasunuma et al, 1997). The potential for therapeutic manipulation of apoptosis continues to be a strong driving force for research in this very active area.

The apoptotic process can be divided into three functionally distinct phases (Figure 1):

(1) Induction - a change in the cellular environment leading to the cell activating the mechanism of apoptosis (i.e. entering the execution phase).

(2) Execution - those processes within the cell that result in committal to apoptotic cell death.

(3) Degradation-those events associated with the final disposal of the cell corpse.

The biochemical events of the initiation phase are determined by the nature of the lethal stimulus, and so may vary from one system to another. It is only during the subsequent execution phase that diverse initiation events are translated into a regular pattern of cellular response and the 'decision to die' is made. The final degradation phase is classically discriminated by the internucleosomal fragmentation of nuclear DNA. The focus of this review is our current understanding of the execution phase mechanisms that regulate the decision by cells to commit to apoptotic death.

\section{Well-known molecular regulators of apoptosis}

Genetic studies of the nematode worm Caenorhabditis elegans have provided powerful clues to the identity of molecular species important in controlling apoptosis. These studies identified two $C$. elegans death genes, named Ced-3 and Ced-4, that were required for developmental apoptosis, and a third gene, Ced-9, that inhibits apoptosis (Ellis et al, 1991).

\section{The caspases}

The first human homologue of Ced-3 identified was interleukin- $1 \beta$-converting enzyme (ICE), which was already known as the enzyme responsible for the proteolytic cleavage of the pro-inflammatory cytokine pro-interleukin $1 \beta$ (Yuan et $a l, 1993)$. Subsequent studies revealed the existence of a large family of related protease enzymes, currently ten in number, each sharing the unusual property of being cysteine proteases with specificity for cleaving substrates on the carboxyl side of aspartate residues. A systematic nomenclature for this family of enzymes has recently been adopted (Alnemri et al, 1996) in which the generic name 'caspase' (casp-ase) alludes to the two family characteristics just 


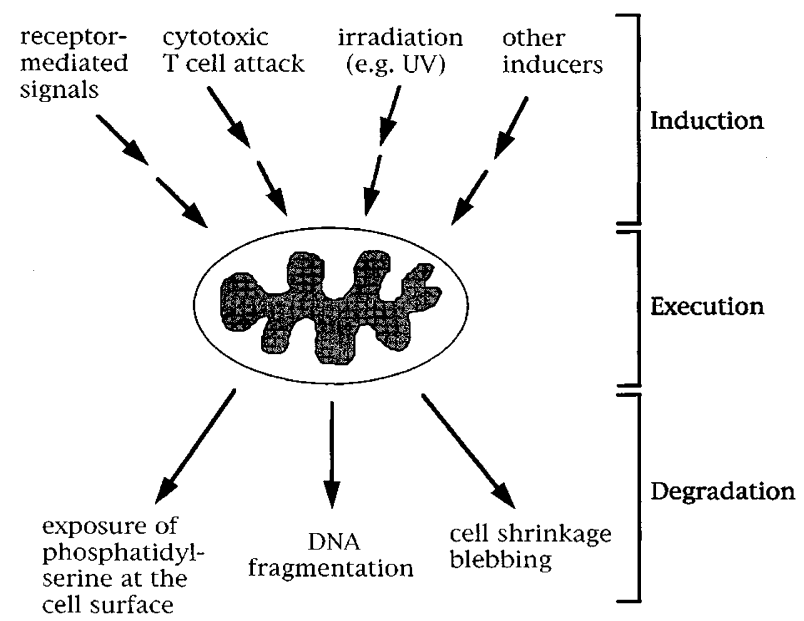

Figure 1 The three phases of apoptosis. Many independent lines of evidence suggest that mitochondrial events occurring during the execution phase act as the switch committing cells to apoptotic death

described. The individual human caspases are numbered on the basis of their chronological order of discovery. Thus, ICE is now also known as caspase-1. The caspases are all synthesised as pro-enzymes which are proteolytically activated by removal of the pro-domain and one or more cleavages of the remaining polypeptide chain to produce two subunits of unequal size. In the case of caspase-1, the active form of the enzyme is a $(\mathrm{p} 20)_{2}-(\mathrm{p} 10)_{2}$ heterotetramer (Whyte, 1996).

Many different cellular protein substrates have been identified for the caspases (reviewed in (Nicholson and Thornberry, 1997; Patel et al, 1996)). In addition to autoactivation and activation of other caspases, caspases are thought to participate in apoptosis by disabling important cellular processes and breaking down structural components of the cell (Nicholson and Thornberry, 1997). There is also evidence that caspases are an important component of the mechanism of apoptotic execution (discussed below). As activation of caspase-3 (CPP32) has been implicated in virtually all apoptotic systems tested, current evidence is consistent with caspase-3 or closely related caspases being a critical component in most if not all apoptotic signalling pathways (Chinnaiyan and Dixit, 1996; Miller, 1997). It appears likely that multiple caspases function together to form proteolytic cascades involved in apoptotic signal transduction (Enari et al, 1996; Greidinger et al, 1996; Whyte, 1996). For example, the demonstration that FLICE (FADD-like ICE; caspase-8) associates with activated CD95 (Fas) suggests that in Fas-mediated apoptosis FLICE may be the apical component of a proteolytic cascade made up of other caspases (Chinnaiyan and Dixit, 1997). This is supported by the demonstration that FLICE can activate all other known caspases (Srinivasula et al, 1996). However, it has not been demonstrated in intact cells that a caspase cascade initiated by FLICE is the exclusive mechanism of Fas-mediated apoptosis.

\section{The bcl-2 family}

The first identified mammalian Ced-9 homologue was bcl-2, originally reported as an oncogene (Tsujimoto et al, 1985), which has been shown to inhibit cell death in many different models of apoptosis (Chinnaiyan and Dixit, 1996; Hawkins and Vaux, 1997). A number of bcl-2-related molecules have been identified. These include $b c l-x_{L}$, which, like $b c l-2$, suppresses apoptosis, and Bax, Bik and Bak, which activate apoptosis (Orth and Dixit, 1997). Bcl-2 family members can form homo- and heterodimers, and these associations are thought to be one means by which their effects on apoptosis are regulated (Chinnaiyan and Dixit, 1996). Bcl-2 is known to be associated with membranes of the nuclear envelope, the endoplasmic reticulum and, particularly, the outer membrane of mitochondria (Nunez and Clarke, 1994). The threedimensional structure of bcl- $x_{L}$ has been shown to be similar to that of the pore-forming domains of bacterial toxins (Muchmore et al, 1996). In addition, it has been shown that bcl-2, bcl- $x_{L}$ and Bax can insert into artificial lipid bilayers to form ion-conducting channels (Minn et al, 1997; Schendel et al, 1997; Schlesinger et al, 1997). These findings suggest that bcl-2 family members may exert their effects on apoptosis by way of controlling ion fluxes between compartments within the cell. There is also evidence suggesting that $b c l-x_{L}$ may regulate mechanisms for homeostatic control of the mitochondrial transmembrane potential $\left(\psi_{\text {mit }}\right)$ and the volume of the matrix (Vander Heiden et al, 1997).

\section{The re-emergence of mitochondria}

Several years ago, reactive oxygen species (ROS), which arise within cells primarily as a by-product of mitochondrial respiratory electron transport, were implicated in many models of apoptosis (Buttke and Sandstrom, 1994). At the time this issue attracted considerable research attention. However, the focus shifted with the emergence of the caspase enzymes and a number of demonstrations that shed doubt on the suggestion that ROS were critical components of the apoptotic machinery. Two such demonstrations were that Fas-induced apoptosis does not require generation of ROS (Schulze-Osthoff et al, 1994) and that cells lacking a functional mitochondrial electron transport chain still undergo apoptosis (Zamzami et al, 1996b).

More recently, interest in the involvement of mitochondria in apoptosis has been revived. This followed the demonstration that in many cases cells undergoing apoptosis show a large reduction in $\psi_{\text {mit }}$ before they show signs of fragmentation of nuclear DNA. This was demonstrated for many cell types (both in vitro and in vivo) and in response to a wide variety of inducing conditions (reviewed in Kroemer et al, 1997). This reduction in $\psi_{\text {mit }}$ is thought to result from a phenomenon, extensively studied using isolated mitochondria in vitro, referred to as the permeability transition (PT). Although many details remain to be established, it appears that PT results from the opening of 'pores' at points of junction between the inner and outer membranes of the mitochondria. The pores are thought to be multi-protein assemblages, incorporating the adenine nucleotide translocator 
(ANT) in the inner mitochondrial membrane and possibly other proteins in the outer mitochondrial membrane, including the peripheral benzodiazepine receptor (Zoratti and Szabo, 1995). The function of PT in normal cell physiology remains uncertain. It has been postulated that periodic reversible PT pore opening may allow for the release of $\mathrm{Ca}^{2+}$ from the mitochondrial matrix, thus ensuring calcium homeostasis (Kroemer et al, 1997). An alternative suggestion is that reversible PT may be useful as a heat-generating mechanism in organisms or tissues which do not possess sufficient brown adipose tissue (Zoratti and Szabo, 1995).

Solute exclusion/permeation studies with polyethylene glycol suggest that PT pores allow unrestricted passage of molecules less than 1500 daltons in either direction across the mitochondrial membranes (Zoratti and Szabo, 1995). However, interestingly, it has also been reported that PT can trigger the release of proteins from mitochondria (Igbavboa et al, 1989; Inoue et al, 1993). The opening of PT pores results in the collapse of the electrochemical gradient produced by the respiratory electron transport chain, which can be detected in intact cells as a marked loss of $\psi_{\text {mit. }}$ It is important to note that there are various ways in which a decrease in $\psi_{\text {mit }}$ might result in cells from processes other than PT. Direct evidence for the claim that the decrease in $\psi_{\text {mit }}$ shown in apoptotic cells results from $\mathrm{PT}$ rests largely on the demonstrations that specific ligands of the ANT (a putative PT pore protein) inhibit PT in isolated mitochondria in vitro and the loss of $\psi_{\text {mit }}$ in apoptotic cells (Zamzami et al, 1996a).

Two models of apoptotic execution in which mitochondria play a pivotal role will be discussed next. However, before moving onto this it is important to note that organelles other than mitochondria may also be important in triggering execution. For example, a recent report suggests that caspase-mediated generation of an $\mathrm{N}$ terminal $20 \mathrm{kDa}$ fragment of the human protein p28 Bap31 from the endoplasmic reticulum induces apoptotic nuclear changes ( $\mathrm{Ng}$ et al, 1997).

\section{The involvement of mitochondria in apoptosis: Model 1}

As described above, it has been shown that a reduction in $\psi_{\text {mit }}$, consistent with PT, occurs in many varied cell types during apoptosis prior to fragmentation of nuclear DNA. This in itself does not establish that PT triggers degradation phase events such as DNA fragmentation. However, there is direct evidence for an involvement of PT in apoptotic execution. In a cell-free system, mitochondria isolated from apoptotic murine liver cells were shown to induce 'nuclear apoptosis' (i.e. nuclear condensation and DNA fragmentation) in nuclei isolated from normal HeLa cells. Furthermore, it was shown that mitochondria isolated from cells overexpressing $\mathrm{Bcl}-2$ did not undergo PT and could not induce nuclear apoptosis in vitro and that pharmacological inhibition of PT inhibited apoptosis in intact murine lymphocytes (Zamzami et al, 1996a,b). Zamzami et al showed that triggering of nuclear apoptosis in vitro was due to the PT-associated release of a protein from mitochondria (Zamzami et al, 1996b). This protein, named 'apoptosis inducing factor' (AIF), is a constitutively expressed $50 \mathrm{kDa}$ protein which resides in the intermembrane space of mitochondria. It appears to be ubiquitous and phylogenetically conserved, since mouse AIF induces apoptosis of human nuclei and vice versa (Kroemer et al, 1997). Interestingly, the action of AIF on nuclei is inhibited by z-VAD.fmk, a tripeptide inhibitor of caspases. However, AIF is not a caspase; preliminary $\mathrm{N}$ terminal sequence analysis indicates that murine AIF is coded for by a novel gene (Susin et al, 1996). PT-mediated swelling of the mitochondrial matrix may burst the outer membrane and release AIF to the cytosol. Rupture of the outer membrane of mitochondria, which swell when undergoing $\mathrm{PT}$ in vitro, has been proposed to explain the release of a variety of mitochondrial proteins (Igbavboa et al, 1989).

It has been proposed that mitochondrial PT is a critical triggering event in the execution phase of apoptosis, acting as a check-point before the initiation of degradation phase events (e.g. DNA fragmentation and exposure of phosphatidylserine at the cell surface) (Marchetti et al, 1996). Mitochondrial PT is regulated by a diverse range of factors, including mitochondrial trans-membrane voltage, oxidation of mitochondrial thiol groups, matrix $\mathrm{pH}$ and the concentration of divalent cations and adenine nucleotides (Zoratti and Szabo, 1995). The regulation of mitochondrial PT by multiple physiological parameters provides a feasible explanation of how so many diverse agents can elicit apoptosis, something that is difficult to accomplish with a model in which caspases alone control apoptosis.

A number of recent findings have contributed to further development of models for the involvement of mitochondria in apoptotic execution. Firstly, a caspase-1-like activity was detected in cells shortly after induction of apoptosis by Fas cross-linking and before a reduction in $\psi_{\text {mit. }}$. Secondly, it was shown that both recombinant caspase-1 and cytosols prepared from anti-Fas treated cells induced PT in isolated mitochondria in vitro. Lastly, it was shown that AIF proteolytically activates recombinant caspase-3 in vitro

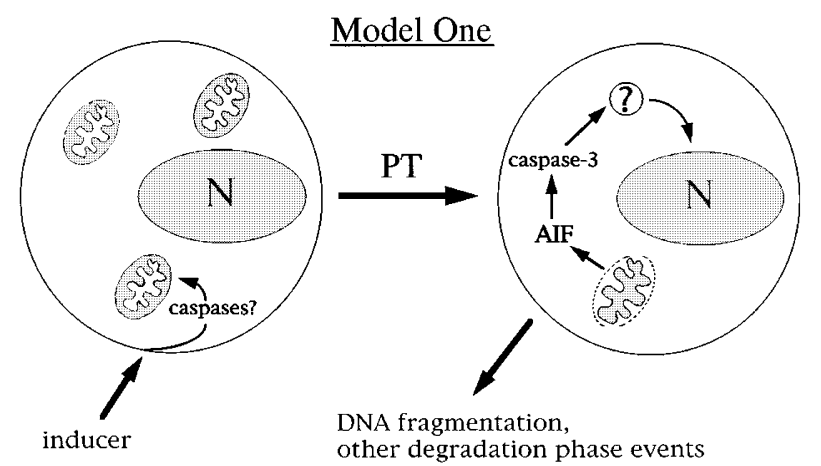

Figure 2 A theorectical model of execution (Model 1) in which the critical triggering event is mitochondrial PT. In this model, inducing signals cause PT, possibly (in some cases) by direct action of caspases on the mitochondria. AIF is released from mitochondria to the cytosol as a result of PT, possibly following PT-induced rupture of the outer membrane. Cytosolic AIF activates caspase-3 and possibly other unidentified molecules to elicit fragmentation of nuclear DNA. The relationship between AIF and the initiation of other degradation phase events is presently unclear 
(Susin et al, 1997). On the basis of these results it has been proposed that a caspase-1-like activity is responsible for triggering mitochondrial $\mathrm{PT}$, resulting in the release of AIF and the downstream activation of caspase-3 and DNA fragmentation (Susin et al, 1997) (Model 1, Figure 2). When considering this model, it is important to note that (i) there is currently no direct evidence that for intact cells the release of AIF to the cytosol triggers DNA fragmentation or that activation of caspase- 3 is dependent on mitochondrial PT, (ii) there has not yet been confirmation of the existence of AIF from a laboratory independent from that responsible for the original reports and (iii) it is not yet known whether caspases are involved in triggering PT in cells induced to undergo apoptosis by treatments other than anti-Fas crosslinking.

\section{The involvement of mitochondria in apoptosis: Model 2}

\section{The release of cytochrome c}

Mitochondria are also implicated in what may be an entirely different pathway for the induction of DNA fragmentation during apoptosis. Using cell-free systems, it was shown by two independent groups that cytochrome c (an extrinsic protein on the outer surface of the inner mitochondrial membrane) was released from mitochondria during apoptosis and triggered the activation of caspase-3, which then in turn triggered processes resulting in DNA fragmentation (Kluck et al, 1997a,b; Liu et al, 1996). An 85 kDa heterodimeric protein, named DNA fragmentation factor (DFF), has been identified as the substrate which is proteolytically activated by caspase-3 before itself directly initiating DNA fragmentation (Liu et al, 1997).

The release of cytochrome $\mathrm{c}$ from mitochondria was shown to be independent of mitochondrial depolarisation (and hence mitochondrial PT) both in a cell-free system and in intact HL60 cells and to be inhibited by overexpression of bcl-2 (Kluck et al, 1997a; Yang et al, 1997). Furthermore, it was shown that in etoposide- or staurosporine-induced apoptosis of HL60 cells, DNA fragmentation preceded loss of mitochondrial $\psi_{\text {mit }}$ and coincided with the release of cytochrome $c$ to the cytosol (Yang et al, 1997). Cytochrome $\mathrm{c}$ release has also been reported to precede loss of $\psi_{\text {mit }}$ in Ara-C-induced HL-60 cells (Kim et al, 1997). In addition, it has been reported that in apoptosis of CEM or HeLa cells induced by UVB irradiation or staurosporine, cytochrome $c$ release precedes or coincides with DEVDspecific caspase activation, proteolysis of pro-caspase-3 and cleavage of PARP (poly(ADP-ribose) polymerase). All these events were shown to occur substantially before loss of $\psi_{\text {mit }}$ (Bossy-Wetzel et al, 1998). Lastly, one other report dealing with intact cells has described release of cytochrome $\mathrm{c}$ to the cytosol prior to loss of $\psi_{\text {mit. }}$ This was reported for (i) Jurkat cells treated with staurosporine or anti-Fas antibody, and (ii) FL5.12 (pro-B) cells induced to undergo apoptosis by withdrawal of IL-3 (Vander Heiden et al, 1997). However, this study did not determine the timing of DNA fragmentation relative to either cytochrome $\mathrm{C}$ release or loss of $\psi_{\text {mit }}$.
Interestingly, the integrity of the outer mitochondrial membrane is lost during apoptosis of Jurkat and FL5.12 cells before loss of $\psi_{\text {mit }}$, consistent with the timing of cytochrome c release. This loss of integrity appears to follow swelling of the volume of the matrix and could provide a mechanism for the release of cytochrome $c$ and other intermembrane proteins (Vander Heiden et al, 1997). The trigger for swelling of the matrix and the loss of integrity of the outer membrane has not yet been determined. Conceivably, this could involve the direct action of an upstream caspase on mitochondria, as suggested for triggering of PT in Fas-mediated apoptosis (Susin et al, 1997). However, overexpression of p35, which is thought to inhibit a range of caspases including caspase1, -2, -3 and -6 (Xue and Horvitz, 1995), did not prevent release of cytochrome $\mathrm{c}$ to the cytosol during apoptosis of gamma-irradiated U937 cells (Kharbanda et al, 1997). Therefore, at least in some cases, release of cytochrome $c$ may be triggered by a caspase-independent mechanism.

\section{Implications of a newly discovered human homologue of Ced-4}

Xiaodong Wang's group demonstrated that two protein fractions obtained from cytosols of apoptotic cells were required to activate caspase-3 in vitro (Liu et al, 1996). These fractions were named Apaf1 (apoptosis activating factor 1) and Apaf2. Apaf2 was identified as cytochrome c, while Apaf1 was subsequently resolved into two active components, finally identified as pro-caspase- 9 and the first human homologue of Ced-4 (Li et al, 1997b; Zou et al, 1997). The human homologue of Ced-4 will be referred to as hhCed4. hhCed-4 has been shown to mediate the formation of a tetramolecular complex involving multiple binding interactions with key molecules regulating apoptosis. Specifically, it has been shown that in the presence of cytochrome $c$ and dATP, hhCed- 4 binds to the $\mathrm{N}$-terminus of pro-caspase- 9 . The formation of this complex in vitro results in activation of caspase-9 which in turn activates caspase-3 (Li et al, 1997b). Thus, experiments performed in vitro suggest that interactions between hhCed-4, pro-caspase-9, cytochrome $c$ and dATP mediate activation of caspase-3, leading to DNA fragmentation and possibly other events of the degradation phase of apoptosis. It has been independently reported that Ced-4, when expressed in transfected mammalian cells, promotes apoptosis and binds to both Ced- 9 and bcl- $x_{L}$ expressed in the same cells. These binding interactions were shown to inhibit the pro-apoptotic activity of Ced-4. Another complication is introduced by the report that $b c l-x_{L}$ can bind directly to cytochrome c (Kharbanda et al, 1997). So what are the implications of these apparently 'promiscuous' binding interactions for our understanding of the execution phase of apoptosis?

On the basis of the above, it is tempting to propose a model (Model 2) in which hhCed-4 is bound to the outer mitochondrial membrane via interaction with $b c l-x_{L}$ or bcl-2. In this hypothetical scheme (Figure 3 ), the trigger for the activation of caspase-3 is comprised of two events. Firstly, the release of cytochrome $c$ from the intermembrane space of the mitochondria and, secondly, release of hhCed-4 from 


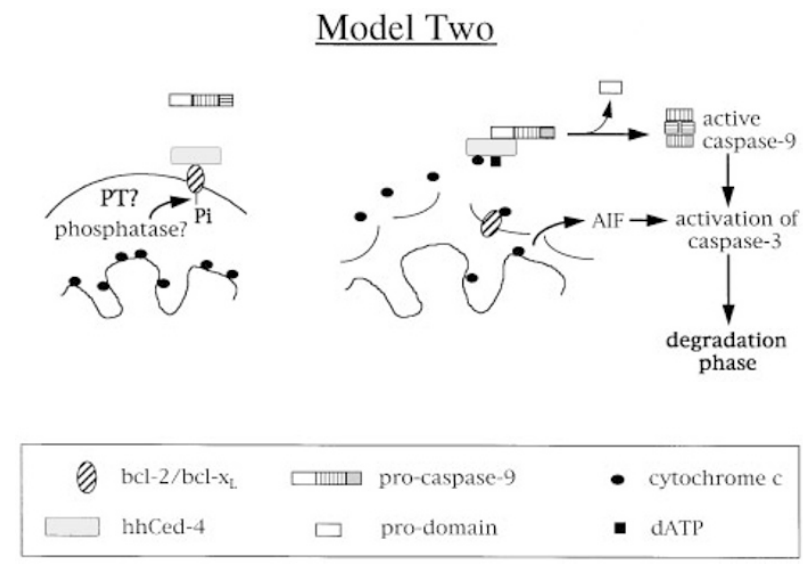

Figure 3 A second theoretical model of execution (Model 2) involving the recently discovered hhCed-4 molecule. Cytochrome $\mathrm{C}$ and AIF are released from the mitochondrial intermembrane space following osmotic swelling of the matrix and rupture of the outer membrane. Swelling of the matrix is triggered by either (i) PT, or (ii) de-phosphorylation of $b c l-2 / b c l-x_{L}$ leading to changes in ion transport processes regulating mitochondrial volume homeostasis. The cytochrome $c$ released binds to hhCed-4 and perhaps also bcl-2/bcl- $x_{\mathrm{L}}$. One or both of these binding events produces conformational changes resulting in the release of hhCed-4/cytochrome c complex from the outer surface of the mitochondria. When the released hhCed-4/cytochrome $c$ complex has bound both dATP and pro-caspase-9, active caspase- 9 is released from the complex to activate caspase-3 and trigger degradation phase events. AIF may also directly activate caspase-3 and provide a complementary pathway for eliciting degradation events

the outer surface of the mitochondria. It is likely that these two events are intimately related and occur effectively at the same time. It is possible that swelling of the matrix compromises the integrity of the outer membrane and releases cytochrome $c$. The swelling of the matrix may be triggered by PT (discussed above) or may involve changes in phosphorylation of bcl-2, which have been shown to regulate the ability of bcl-2 to protect cells from apoptosis (Ito et al, 1997). Recent evidence suggests that bcl- $x_{L}$ can regulate the volume homeostasis of mitochondria (Vander Heiden et al, 1997). Thus changes in phosphorylation of $\mathrm{bcl}-2 / \mathrm{bcl}-\mathrm{x}_{\mathrm{L}}$ may lead to PT-independent disruption of the outer membrane and release of cytochrome $c$. The released cytochrome $c$ could then bind to $b c l-2 / b c l-x_{L}$ and/or hhCed-4 at the outer surface of the mitochondria. This may cause a conformational change, disrupting the interaction between $\mathrm{hhCed}-4$ and $\mathrm{bcl}-2 / \mathrm{bcl}-\mathrm{x}_{\mathrm{L}}$ to result in release of hhCed/cytochrome c complex into the cytosol. Cytosolic hhCed-4/cytochrome c may then bind with dATP and pro-caspase-9 to generate active caspase-9, which finally activates caspase-3 (Figure 3).

When considering Model 2, it is important to note that (i) in many cell types, a reduction in $\psi_{\text {mit }}$ precedes DNA fragmentation (Kroemer et al, 1997), (ii) cytochrome c is released from isolated rat liver mitochondria induced to undergo PT in vitro (Kantrow and Piantadosi, 1997), (iii) microinjection of kidney 293 cells with cytochrome c elicits apoptosis (Duckett et al, 1998; Li et al, 1997a), (iv) multiple myeloma cells release cytochrome $\mathrm{c}$ to the cytosol when induced to undergo apoptosis by ionizing radiation but not when induced by dexamethasone or anti-Fas antibody (Chauhan et al, 1997) (v) the association of hhCed-4 with $\mathrm{bcl}-2 / \mathrm{bcl}-\mathrm{x}_{\mathrm{L}}$ at the outer surface of mitochondria has not been established. It has been proposed that AIF and cytochrome c may be components of complementary or alternative pathways for triggering DNA fragmentation during apoptosis (Yang et al, 1997).

\section{Conclusions}

In the last 2 years vast strides have been made in our understanding of the critical components and processes that control apoptosis. It is now reasonable to assume that most of the major molecules important in executing apoptosis are known. However, there are still many questions that remain unanswered. It is clear that there are some cell systems in which mitochondrial PT is not necessary for the onset of degradation phase events. The extent to which $\mathrm{PT}$ is required to elicit degradation phase events in different types of cells and in response to different inducers of apoptosis requires clarification. Likewise, although the demonstrations of the importance of cytochrome c, and now hhCed-4, in apoptotic execution are exciting, it is prudent to realize that the amount of data pertaining to this originating from studies of intact cells is currently very limited. Consequently, further studies with whole cells will be valuable in establishing the generality of the involvement of cytochrome $\mathrm{c}$ and hhCed-4 in different physiological models of apoptosis. Studies of intact cells that examine both the occurrence of mitochondrial PT and the release of cytochrome $c$ (and perhaps also hhCed-4) to the cytosol will be of particular importance since they will allow us to better characterise the diversity of physiological mechanisms of execution. The recent in vitro demonstration that the hhCed-4 molecule can physically link pro-caspase-9, cytochrome $\mathrm{c}$ and dATP to form a caspase-3-activating complex has profound implications for our understanding of the mechanisms of apoptotic execution. This pioneering discovery must now be followed with extensive work to test the predictions it has spawned in the unit of organisation for which apoptosis evolved, the cell.

\section{Note added in proof}

During review of this manuscript, several important papers impinging on its subject matter were published. Firstly, direct evidence has been produced that bcl-2 regulates proton flux across the inner mitochondrial membrane (Shimizu et al, 1998). Secondly, it has now been demonstrated that, when co-expressed in mammalian cells, bcl- $x_{L}$ forms a ternary complex with pro-caspase- 9 and hhCed-4 (Pan et al, 1998). In addition, it appears likely that the $40 \mathrm{kDa}$ and $45 \mathrm{kDa}$ subunits of DFF (isolated from human cells) correspond, respectively, to the recently reported caspase-activated DNAse (CAD) and inhibitor of caspaseactivated DNAse (ICAD) proteins purified from murine cells (Enari et al, 1998). 


\section{References}

Alnemri ES, Livingston DJ, Nicholson DW, Salvesen G, Thornberry NA, Wong WW and Yuan JY (1996) Human ICE/Ced-3 Protease Nomenclature. Cell 87: 171

Bossy-Wetzel, E, Newmeyer, DD and Green, DR (1998) Mitochondrial cytochrome c release in apoptosis occurs upstream of DEVD-specific caspase activation and independently of mitochondrial transmembrane depolarization. EMBO J. 17: $37-49$

Buttke TM and Sandstrom PA (1994) Oxidative stress as a mediator of apoptosis. Immunol. Today 15: 7-10

Chauhan D, Pandey P, Ogata A, Teoh G, Krett N, Halgren R, Rosen S, Kufe D, Kharbanda S and Anderson K (1997) Cytochrome c-dependent and independent induction of apoptosis in multiplle myeloma cells. J. Biol. Chem. 272: $29995-29997$

Chinnaiyan AM and Dixit VM (1996) The cell death machine. Curr. Biol. 6: 555-562

Chinnaiyan AM and Dixit VM (1997) Portrait of an executioner: the molecular mechanism of FAS/APO-1-induced apoptosis. Semin. Immunol. 9: $69-76$

Duckett CS, Li F, Wang Y, Tomaselli KJ, Thompson CB and Armstrong RC (1998) Human IAP-like protein regulates programmed cell death downstream of $\mathrm{Bcl}-\mathrm{X}_{\mathrm{L}}$ and cytochrome c. Mol. Cell. Biol. 18: 608-615

Ellis RE, Yuan J and Horvitz HR (1991) Mechanisms and functions of cell death. Ann. Rev. Cell. Biol. 7: 663-698

Enari M, Talanian RV, Wong WW and Nagata S (1996) Sequential activation of ICElike and CPP32-like proteases during Fas-mediated apoptosis. Nature 380: $723-726$

Enari M, Sakahira H, Yokoyama H, Okawa K, Iwamatsu A and Nagata S (1998) A caspase-activated DNase that degrades DNA during apoptosis, and its inhibitor ICAD. Nature 391: 43-50

Greidinger EL, Miller DK, Yamin TT, Casciola-Rosen L and Rosen A (1996) Sequential activation of three distinct ICE-like activities in Fas-ligated Jurkat cells. FEBS Lett. 390: 299-303

Hasunuma T, Kayagaki N, Asahara H, Motokawa S, Kobata T, Yagita H, Aono H, Sumida T, Okumura K and Nishioka K (1997) Accumulation of soluble Fas in inflamed joints of patients with rheumatoid arthritis. Arthritis \& Rheumatism 40: $80-86$

Hawkins CJ and Vaux DL (1997) The role of the Bcl-2 family of apoptosis regulatory proteins in the immune system. Semin. Immunol. 9: 25-33

Igbavboa U, Zwizinski CW and Pfeiffer DR (1989) Release of mitochondrial matrix proteins through a $\mathrm{Ca}^{2+}$-requiring, cyclosporin-sensitive pathway. Biochem. Biophys. Res. Commun. 161: 619-625

Inoue T, Yoshida Y, Nishimura M, Kurosawa K and Tagawa K (1993) $\mathrm{Ca}^{2+}$-induced, phospholipase-independent injury during reoxygenation of anoxic mitochondria. Biochim. Biophys. Acta 1140: 313-320

Ito T, Deng XM, Carr B and May WS (1997) Bcl-2 phosphorylation required for antiapoptosis function. J Biol Chem 272: 11671-11673

Kantrow SP and Piantadosi CA (1997) Release of cytochrome c from liver mitochondria during permeability transition. Biochem. Biophys. Res. Commun. 232: $669-671$

Kharbanda S, Pandey P, Schofield L, Israels S, Roncinske R, Yoshida K, Bharti A, Yuan ZM, Saxena S, Weichselbaum R, Nalin C and Kufe D (1997) Role For Bcl$X_{L}$ as an inhibitor of cytosolic cytochrome $c$ accumulation in DNA damageinduced apoptosis. Proc. Nat. Acad. Sci. USA 94: 6939-6942

Kim CN, Wang XD, Huang Y, Ibrado AM, Liu L, Fang GF and Bhalla K (1997) Overexpression of $\mathrm{Bcl}-\mathrm{X}_{\mathrm{L}}$, inhibits Ara-c-induced mitochondrial loss of cytochrome $\mathrm{c}$ and other perturbations that activate the molecular cascade of apoptosis. Cancer Res. 57: 3115-3120

Kluck RM, Bossywetzel E, Green DR and Newmeyer DD (1997a) The release of cytochrome $\mathrm{c}$ from mitochondria - a primary site for $\mathrm{Bcl}-2$ regulation of apoptosis. Science 275: $1132-1136$

Kluck RM, Martin SJ, Hoffman BM, Zhou JS, Green DR and Newmeyer DD (1997b) Cytochrome $\mathrm{c}$ activation of CPP32-like proteolysis plays a critical role in a Xenopus cell-free apoptosis system. EMBO J. 16: 4639-4649

Kroemer G, Zamzami N and Susin S (1997) Mitochondrial control of apoptosis. Immunol. Today 18: 44-51

Li F, Srinivasan A, Wang Y, Armstrong RC, Tomaselli KJ and Fritz LC (1997a) Cellspecific induction of apoptosis by microinjection of cytochrome $\mathrm{C}-\mathrm{Bcl}-\mathrm{X}_{\mathrm{L}}$ has activity independent of cytochrome c release. J. Biol. Chem. 272: 30299-30305
Li P, Deepak Nijhawan, Budihardjo I, Srinivasula SM, Ahmad M, Alnemri ES and Wang X (1997b) Cytochrome c and dATP-dependent formation of Apaf-1/ Caspase-9 complex initiates an apoptotic protease cascade. Cell 91: 479-489

Liu XS, Kim CN, Yang J, Jemmerson R and Wang XD (1996) Induction of apoptotic program in cell-free extracts - requirement for dATP and cytochrome c. Cell 86 : $147-157$

Liu XS, Zou H, Slaughter C and Wang XD (1997) DFF, a heterodimeric protein that functions downstream of caspase-3 to trigger DNA fragmentation during apoptosis. Cell 89: 175-184

Marchetti P, Castedo M, Susin SA, Zamzami N, Hirsch T, Macho A, Haeffner A, Hirsch $F$, Geuskens M and Kroemer G (1996) Mitochondrial permeability transition is a central coordinating event of apoptosis. J. Exp. Med. 184: 1155-1160

Minn AJ, Velez P, Schendel SL, Liang H, Muchmore SW, Fesik SW, Fill M and Thompson CB (1997) Bcl- $X_{L}$ forms an ion channel in synthetic lipid membranes. Nature 385: $353-357$

Muchmore SW, Sattler M, Liang H, Meadows RP, Harlan JE, Yoon HS, Nettesheim D, Chang BS, Thompson CB, Wong SL, Ng SL and Fesik SW (1996)X-ray and NMR structure of human $B c l-x_{L}$, an inhibitor of programmed cell death. Nature 381 : $335-341$

Nicholson DW and Thornberry NA (1997) Caspases-killer proteases. Trends Biochem. Sci. 22: 299-306

Ng FWH, Nguyen M, Kwan T, Branton PE, Nicholson DW, Cromlish JA and Shore GC (1997) P28 Bap31, a Bcl-2/Bcl-X $\mathrm{X}_{\mathrm{L}}$ - and Procaspase-8-Associated Protein In the Endoplasmic Reticulum. J. Cell. Biol. 139: 327-338

Nunez G and Clarke MF (1994) The Bcl-2 family of proteins: regulators of cell death and survival. Trends Cell. Biol. 4: 399-403

Orth R and Dixit VM (1997) Bik and Bak induce apoptosis downstream of Crma but upstream of inhibitor of apoptosis. J. Biol. Chem. 272: 8841-8844

Pan G, O'Rourke K and Dixit V (1998) Caspase-9, Bcl- $x_{\mathrm{L}}$ and Apaf-1 form a ternary complex. J. Biol. Chem. 273: 5841-5845

Patel T, Gores GJ and Kaufmann SH (1996) The role of proteases during apoptosis. FASEB J. 10: $587-597$

Schendel SL, Xie ZH, Montal MO, Matsuyama S, Montal M and Reed JC (1997) Channel formation by antiapoptotic protein Bcl-2. Proc. Nat. Acad. Sci. USA 94: 5113-5118

Schlesinger PH, Gross A, Yin XM, Yamamoto K, Saito M, Waksman G and Korsmeyer SJ (1997) Comparison of the ion channel characteristics of proapoptotic Bax and antiapoptotic Bcl-2 Proc. Nat. Acad. Sci. USA 94: 11357-11362

Schulze-Osthoff K, Krammer PH and Droege W (1994) Divergent signalling via APO$1 /$ Fas and the TNF receptor, two homologous molecules involved in physiological cell death. EMBO J. 13: 4587-4598

Schulze-Osthoff K, Krammer PH and Droege W (1994) Divergent signalling via APO$1 /$ Fas and the TNF receptor, two homologous molecules involved in physiological cell death. EMBO J. 13: 4587-4598

Shimizu S, Eguchi Y, Kamiike W, Funahashi Y, Mignon A, Lacronique V, Matsuda H and Tsujimoto $Y$ (1998) Bcl-2 prevents apoptotic mitochondrial dysfunction by regulating proton flux. Proc. Nat. Acad. Sci. USA 95: 1455-1459

Srinivasula SM, Ahmad M, Fernandesalnemri T, Litwack G and Alnemri ES (1996) Molecular ordering of the Fas-apoptotic pathway - the Fas/Apo-1 protease Mch5 is a Crma-inhibitable protease that activates multiple Ced-3/ICE-like cysteine proteases. Proc. Nat. Acad. Sci. USA 93: 14486-14491

Susin SA, Zamzami N, Castedo M, Daugas E, Wang HG, Geley S, Fassy F, Reed JC and Kroemer G (1997) The central executioner of apoptosis - multiple connections between protease activation and mitochondria in Fas/Apo-1/ CD95- and ceramide-induced apoptosis. J. Exp. Med. 186: 25-37

Susin SA, Zamzami N, Castedo M, Hirsch T, Marchetti P, Macho A, Daugas E, Geuskens M and Kroemer G (1996) Bcl-2 inhibits the mitochondrial release of an apoptogenic protease. J. Exp. Med. 184: 1331-1341

Tsujimoto Y, Cossman E, Jaffe E and Croce CM (1985) Science 228: 1440-1443

Vander Heiden MG, Chandel NS, Williamson EK, Schumacker PT and Thompson CB (1997) Bcl- $\mathrm{X}_{\mathrm{L}}$ regulates the membrane potential and volume homeostasis of mitochondria. Cell 91: $627-637$

Whyte M (1996) Ice/Ced-3 proteases In apoptosis. Trends Cell. Biol. 6: 245- 248

Xue D and Horvitz HR (1995) Inhibition of the Caenorhabditis elegans cell-death protease Ced-3 by a Ced-3 cleavage site in baculovirus p35 protein. Nature 377 $248-251$

Yang J, Liu XS, Bhalla K, Kim CN, Ibrado AM, Cai JY, Peng TI, Jones DP and Wang XD (1997) Prevention of apoptosis by Bcl-2 - release of cytochrome c from mitochondria blocked. Science 275: 1129-1132 
Yuan JY, Shaham S, Ledoux S, Ellis HM and Horvitz HR (1993) The C-elegans cell death gene Ced-3 encodes a protein similar to mammalian interleukin-1-betaconverting enzyme. Cell 75: 641-652

Zamzami N, Marchetti P, Castedo M, Hirsch T, Susin SA, Masse B and Kroemer G (1996a) Inhibitors of permeability transition interfere with the disruption of the mitochondrial transmembrane potential during apoptosis. FEBS Lett. 384: 53 57

Zamzami N, Susin SA, Marchetti P, Hirsch T, Gomezmonterrey I, Castedo M and Kroemer G (1996b) Mitochondrial control of nuclear apoptosis. J Exp Med 183 $1533-1544$
Zoratti M and Szabo I (1995) The mitochondrial permeability transition. Biochim Biophys Acta 1241: 139-176

Zou H, Henzel WJ, Liu XS, Lutschg A and Wang XD (1997) Apaf-1, a human protein homologous to $\mathrm{C}$. elegans Ced-4, participates in cytochrome c-dependent activation of caspase-3. Cell 90: $405-413$ 